\title{
The Benefits of Remote Real-time Pressure Control in Water Distribution Systems
}

\author{
Philip R. Page
}

\begin{abstract}
The additional benefit of a recent highly optimal technique which keeps the pressure low and constant at a remote location, above the conventional technique, is discussed. The former technique is called remote real-time control (RRTC). The reasons for the advantage are clearly elucidated. The direct technical and indirect advantages are pointed out. Substantial additional economic benefit of RRTC obtains under conditions of large leakage, and large operation and maintenance unit cost of water. It is shown that for favourable water distribution system conditions in South Africa, RRTC yields additional life cycle savings of $R 20$ - 100 million (\$ 1.5 - 8 million).
\end{abstract}

Keywords - economic analysis, non-revenue water, pressure management, pressure reducing valve.

\section{INTRODUCTION}

A critical part of saving water is to minimize water loss due to existing infrastructure inefficiency. The maintenance and refurbishment of water infrastructure are the costly first line of defence, and should receive the highest priority from the government. The second line of defence is pressure management (PM) (keeping the water pressure throughout the system within an acceptable range, while still satisfying the needs of customers). This is less costly; and has been demonstrated in the literature to consistently reduce water leakage from pipes [1]. PM also reduces pipe burst frequency; hence ensuring less maintenance and refurbishing of the infrastructure, with accompanying improved service delivery. Moreover, PM may reduce water consumption, often important due to the incidence of non-revenue water (NRW) use. Hence PM does not only save water, but also helps to solve maintenance, refurbishing, service delivery and NRW problems. Service delivery advantages include faster response to problems, reduction of customers' complaints and an improved reputation of the water utility.

\section{Two DifFEREnt Pressure Reducing VALVe Solutions}

PM is the process by which the pressure in a water distribution system (WDS) is set as low as possible. There is a target for the minimum pressure. However, the pressure needs to be set high enough to still satisfy customer needs. The WDS is usually segmented into different pressure management areas (PMA). PM in the different PMAs is mostly independent of each other. The point in the PMA which is sensitive to adjustment of the actuator, and where, if possible, the pressure

Philip R. Page, Council for Scientific and Industrial Research, Pretoria, South Africa. is minimal over time, is called the critical point (CP) (see the example in Fig. 1) [2]. This point is often located at a remote extremity of the WDS.

Historically, PM is most commonly attained by using a pressure reducing valve (PRV). This actuator will be studied since it exemplifies central PM concepts relevant to all actuators, and specific relevant studies have been performed for this actuator. The PRV reduces the pressure to a fixed value immediately downstream of the valve ( $60 \mathrm{~m}$ for the example, as shown in Fig. 2). This solution will be referred to as the conventional PRV solution.

It turns out that the most optimal PM method should not fix the pressure immediately downstream of the PRV, but should fix it in real-time at the target minimum set-point pressure value at the CP (Fig. 3). This second method will be called the RRTC PRV solution (remote real-time control), since it requires wireless electronic communication between the PRV and the remote CP. The RRTC PRV is more complicated and costly than the conventional PRV. Currently, the RRTC PRV is at the cutting edge of technology.

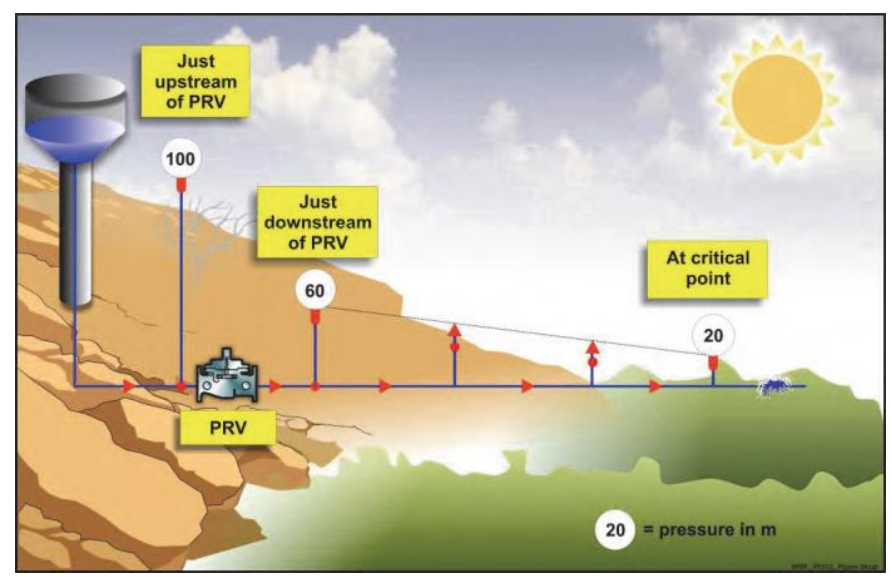

Fig. 1: The effect of a pressure reducing valve on pressure [3]. For comparison to Fig. 2 and Fig. 3 the case of maximal water consumption is shown, reaching the target minimum pressure of $20 \mathrm{~m}$ at the $\mathrm{CP}$.

\section{DiRECT TECHNICAL AND IndiRECT AdVANTAGES OF RRTC}

The conventional PRV is clearly able to reduce the pressure (to $60 \mathrm{~m}$ at the PRV outlet in the example in Fig. 2). However, it does not do this optimally. In Fig. 2 it can be seen that the minimum target pressure is only attained infrequently at the $\mathrm{CP}$. On the other hand, the RRTC PRV reduces the pressure almost optimally (to 20-60 m at the PRV outlet in the example in Fig. 3) 
in such a way that the minimum target pressure is continually attained at the $\mathrm{CP}$ in real-time.

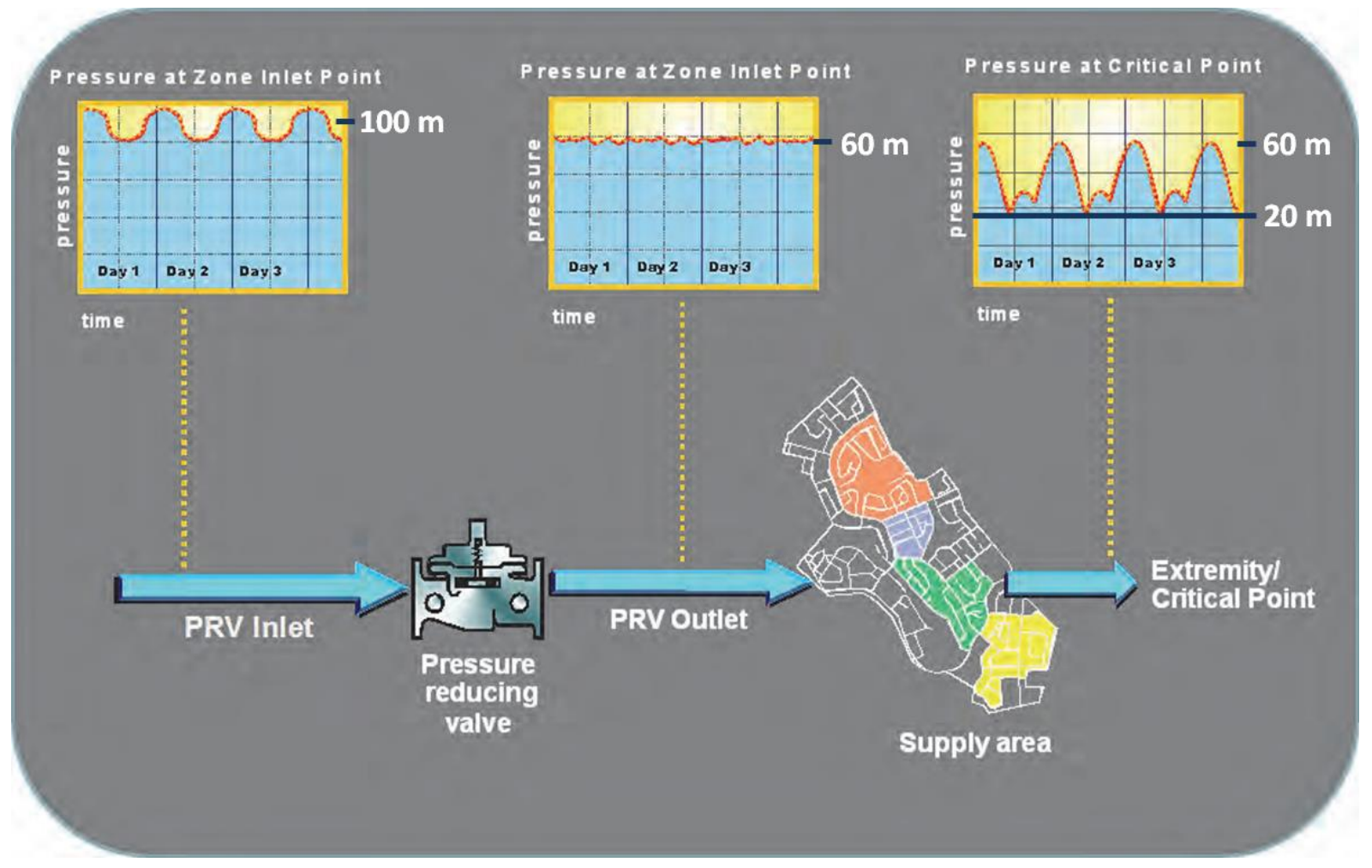

Fig. 2: Conventional PRV. The PRV is located at the inlet of one of the PMAs indicated in the "supply area". Modified from [3]

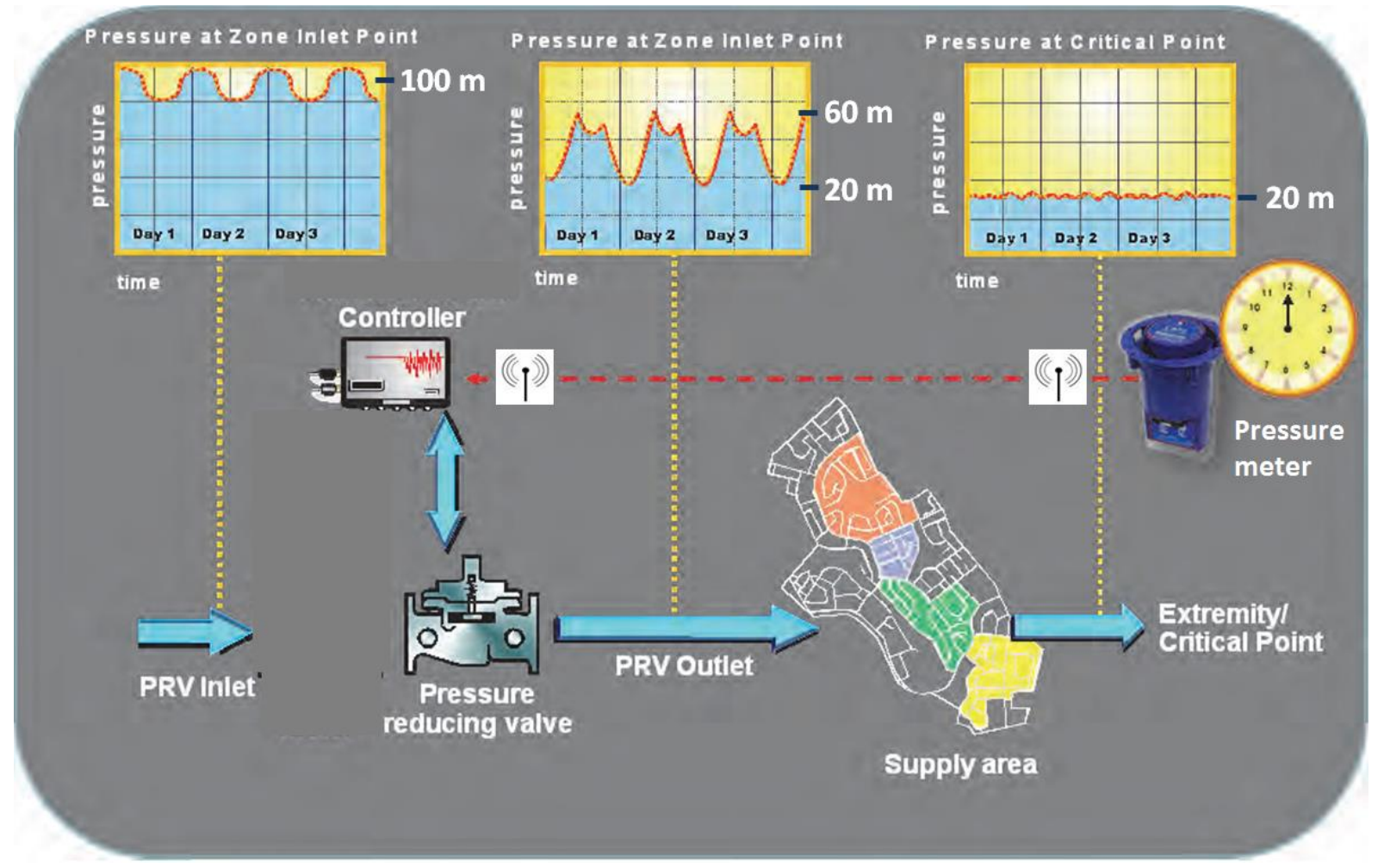

Fig. 3: RRTC PRV. In addition to the conventional PRV, a pressure meter is located at the CP, and a controller at the PRV. Modified from [3].

The conventional PRV offers all the direct technical advantages of pressure reduction, i.e. water leakage reduction, decrease of pipe burst frequency, and possible reduction in water consumption; and hence all the indirect advantages, i.e. 
less maintenance, refurbishing, service delivery and NRW problems. However, the RRTC PRV attains each of these advantages to a greater extent, because it reduces pressure more optimally.

\section{ECONOMIC Advantages Of RRTC}

The above advantages translate into cost reduction for the municipality. A life cycle cost analysis [4] took the following into account to calculate the total cost:

- Installation, equipment and communication costs of the PRV and related components.

- Water-related total operating and maintenance cost, including e.g. the cost of pumping and treatment chemicals.

- Total pipe breakage repair cost.

South Africa has two characteristics, which will be taken to hold for the particular PMA:

- The typical leakage in South African municipalities is $25.4 \%$ (based on the estimate of NRW at 36.8\%) [5].

- Consumer water prices are often much lower than the actual operation and maintenance unit cost of water. This cost is estimated to really be between R14 and R34 per 1000 litre in South Africa [6]. Here, all Rand amounts reflect 2018 Rand. The unit cost is high by international standards.

The high leakage and unit cost make PM particularly important in South Africa. With the two characteristics, there is a net cost saving using either PRV solution [4]. (Remember that the installation, equipment and communication costs were included in calculating the net cost saving). Moreover, the net cost saving is almost always more with the RRTC PRV than with the conventional PRV.

A recent Water Research Commission (WRC) report confirms this: "Based on the results achieved from over 400 PM installations, it appears that the largest saving achieved from a PM installation is usually from the basic fixed outlet pressure control [conventional PRV] ... In most cases, this will provide around $60 \%$ to $70 \%$ of the ultimate savings that can be achieved ... Adding some form of ... closed-loop [e.g. RRTC PRV] ... control will provide the remainder." [3]

Define the amount by which the net cost saving with the RRTC PRV exceeds the net cost saving with the conventional $\mathrm{PRV}$ as the additional saving. The expectation is that this will be largest when there are large pressure fluctuations between peak demand and off-peak demand periods throughout the WDS. Consistent with this expectation, the analysis [4] concludes that the additional saving is particularly large when the following two conditions hold:

- The PMA is large. An example would be a $5 \mathrm{~km}$ by $5 \mathrm{~km}$ area with about 30000 inhabitants.

- The variation of customer water use during the day is large. An example would be a maximum variation of a factor of three from the average.

Under these favourable WDS conditions, the additional saving will be $7 \%$ of total cost [4]. Over a 40 year life cycle, this predicts that the additional saving for the PMA is R $40-100$ million. Assuming half the large customer water consumption assumed in [4], more appropriate to average South African WDSs, the additional saving is R 20 - 50 million. Since a WDS can have numerous PMAs with favourable conditions, the additional saving can be huge!

The cost advantages justify retrofitting an existing conventional PRV to be a RRTC PRV for favourable WDS conditions. Under these conditions, they also imply that a RRTC PRV should be installed instead of a conventional PRV in new installations.

\section{PRINCIPLES OF RRTC}

Due to the advantages above, the application of RRTC in a real WDS using a PRV to change the pressure has rapidly increased internationally from almost none to several from 2010 to 2015 [1]. In addition, the application of RRTC is expected to grow in tandem with the explosion of growth expected for the Internet of Things.

RRTC can more formally be viewed as follows. The water pressure (process variable) can be set to a low and constant set-point by adjusting the setting of an actuator, based on the measurement of pressure by a sensor on a pressure meter (Fig. 4). The amount by which the actuator setting must be adjusted is predicted by a mathematical algorithm called a controller. This process is indicated in Fig. 4. RRTC is hence a form of closed-loop control [3], i.e. a form of remote node modulation [1].

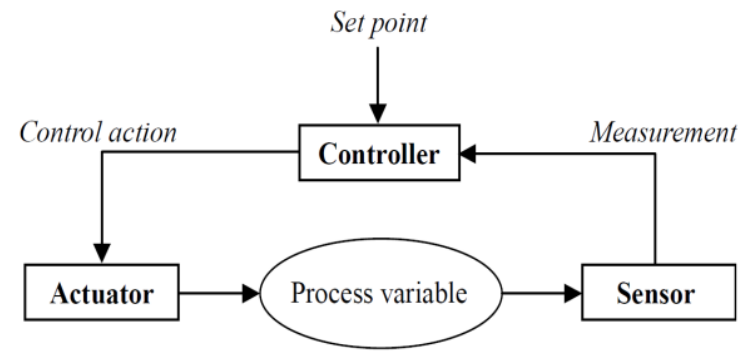

Fig. 4: Sketch of a control loop. Arrows indicate data flows, bold letters indicate hardware components, italic letters indicate transferred information. [7]

\section{DISCUSSION}

Real-time remote control (RRTC) offers a pressure management technique which is highly optimal at reducing pressure, compared to other advanced pressure management techniques currently employed by companies. The authors are unaware of any commercial company which offers an integrated RRTC solution for purchase at this time.

\section{REFERENCES}

[1] D. J. Vicente, L. Garrote, R. Sanchez and D. Santillan, "Pressure management in water distribution systems: Current status, proposals, and future trends," Journal of Water Resources Planning and Management, vol. 142, no. 2, p. 04015061, 2015.. https://doi.org/10.1061/(ASCE)WR.1943-5452.0000589

[2] A. Campisano, E. Creaco and C. Modica, "RTC of valves for leakage reduction in water supply networks," Journal of Water Resources Planning and Management, vol. 136, no. 1, pp. 138-141, 2010. https://doi.org/10.1061/(ASCE)0733-9496(2010)136:1(138) 
[3] R. S. McKenzie, "Guidelines for reducing water losses in South African municipalities," Water Research Commission report TT 595/14. ISBN: 978-1-4312-0565-3, 2014.

[4] E. Creaco and T. Walski, "Economic analysis of pressure control for leakage and pipe burst reduction," Journal of Water Resources Planning and Management, vol. 143, no. 12, 2017. https://doi.org/10.1061/(ASCE)WR.1943-5452.0000846

[5] R. Mckenzie, Z. N. Siqalaba and W. A. Wegelin, "The state of non-revenue water in South Africa," Water Research Commission report TT 522/12. ISBN: 978-1-4312-0263-8, 2012

[6] WIN-SA, "A costing framework for municipalities serving communities in both urban and rural contexts," Water Research Commission report, 2013.

[7] A. Campisano, J. Cabot Ple, D. Muschalla, M. Pleau and P. A Vanrolleghem, "Potential and limitations of modern equipment for real time control of urban wastewater systems," Urban Water Journal, vol. 10, no. 5, p. 300-311, 2013.

https://doi.org/10.1080/1573062X.2013.763996 